\title{
ANN Fed High Gain Luo Converter based Reduced Switch Multilevel Inverter for Single Phase Network Bridged PV Arrangement
}

\author{
S. Prakash, N. P. Gopinath, B. Kalaiselvi
}

\begin{abstract}
In the present scenario photovoltaic (PV) systems feature resonant interest in the recent researches. The amount from the PV frame is highly oscillated due to temperature variation. In this proposed work, the ANN based MPPT algorithm extracts maximum energy from the $P V$ system by benefit of high gain DC-DC Luo converter, the Luo converter produced voltage is given to the single phase grid through reduced switch seven level inverter. The proposed seven level inverter is controlled by high frequency technique multicarrier modulation technique. The PI controller based closed loop grid synchronization is implemented for solving the power quality issues. The multilevel inverter reduce the total harmonics distortion in the output AC voltage waveform. The developed work is carried out using Matlab software-based simulation with various solar irradiation and degree.
\end{abstract}

Keywords: Artificial Neural Network (ANN), Cascade H-Bridge Multilevel inverter (CHB-MLI), Maximum power point tracking (MPPT), Luo Converter, Photovoltaic (PV)

\section{INTRODUCTION}

\section{$\mathrm{S}_{\mathrm{o}}$} power generation across the photovoltaic (PV) system. Even though the primary fault of system is minimal efficiency of conversion into electricity. Henceforth the environmental factors such as solar radiation and atmospheric temperature plays a vital role in power generation by PV modules [1]. Need for solar energy is rising approximately by $20-25 \%$ every year, during the past two decades [2].The potential for direct transformation of $\mathrm{AC}$ energy in affixing to reduced functioning cost and low emissions are the major merits. Hence the unimaginable penetration of PV systems in the power conversion system is understandable [3]. Despite the various benefits of the PV system, its non linear characteristics form a major challenge. A PV array tracking isan important issue for increasing the total efficiency of the system. The output of the PV array varies often with respect to the climate conditions. So a technique called Maximal Power Point Tracking is utilized for extricating the extreme power from the PV panels. In the past, several methods have

Revised Manuscript Received on December 11, 2019.

S. Prakash*, Assistant Professor, Department of Electrical and Electronics Engineering, Aarupadai Veedu Institute of Technology, Chennai, India.

N. P. Gopinath, Assistant Professor, Department of Electrical and Electronics Engineering Aarupadai Veedu Institute of Technology, Chennai, India.

B. KalaiSelvi, Assistant Professor, Department of Electrical and Electronics Engineering, Aarupadai Veedu Institute of Technology, Chennai, India. been presented for evaluating the maximum power point whereas most widely used theorems are Perturb \& Observe $(\mathrm{P} \& \mathrm{O})$ and Increased Conductance [4].

Traditional MPPT techniques achieve moderate performance with few complexities in implementation. Developed artificial intelligence based MPPT technique is advised for better changeable and constant frame action specifically under partial shading and rapidly changing environment [5].Various Artificial Intelligence based MPPT techniques are developed. In that fuzzy logic and Artificial Neural Network controllers are utilized nowadays, whereas Artificial Neural Network has shown better performance under frequently changing irradiance, specifically with respect to efficiency and response time [6]. The developed MPPT with ANN is trained to evaluate the MPP voltage as reference voltage. Thus obtained reference voltage drive the DC to DC Luo converter to function near to MPP [7]. The generated voltage from PV module is not appropriate for rating of network voltage. Hence Luo converter is utilized to improve the rating of voltage through ANN based MPPT method. Thus regulated voltage from Luo converter is DC, but for economic desire, conversion of DC to $\mathrm{AC}$ is essential.

Topologies like cascaded H-Bridge inverter, Diode clamped and flying capacitor are used for DC to AC conversion. [8, 10]. Various types of PV inverters have been developed and designed in the recent years. Among which cascaded H-bridge MLI is developed in this system. Thus suggested methodology allows the usage of DC sources with distinct values of voltages and high resolution multilevel waveforms can be generated with reduced count of components [11]. Less Total Harmonic Distortion (THD), less electromagnetic interference can be achieved with reduced cost of components [12,19].

Various techniques [12] are available in the present scenario for controlling the multilevel inverters like sinusoidal pulse width modulation and vector pulse width modulation. From paper, advanced selected harmonic elimination methodology is utilized for minimizing certain harmonics of lower order like 3rd, 5th and 7th from the output voltage. Distinct non linear equations are solved by this method and a better optimized result can be produced. ANN methodology is utilized for solving non linear equation to reduce THD [6]. The evaluated information is utilized for designing seven level inverter of single phase and simulation model at MATLAB platform. 
In order to overcome all the existing issues, the proposed Luo converter based seven level inverter based single phase connected to solar has designed. The Luo converter having high output voltage gain and internal regenerative snubber circuit. The seven level inverter is achieved with common single DC source with reduced switches. The grid synchronization also achieved using PI controller.

\section{COMPOSITION OF PV SYSTEM}

The solar tracker receives power from the sun and converts daylight into DC energy. A significant part of the PV arrangement is the solar chamber, the solar chamber of the bundled cells panels. Generally the PV cell consists of semiconductor object. The terminal of PV device produce voltage and current to small loads likewise DC motors and lighting systems $[2,13]$. Mathematical layout of PV cell is designed using Mat lab. From the theory the mathematical VI characteristics of PV cell is detailed by [13], [12].

$$
\begin{aligned}
& I=I_{\text {pv,cell }}-I_{d} \\
& I_{d}=I_{o, c e l l} \\
& I=I_{\text {pv,cell }}-I_{0, \text { cell }}
\end{aligned}
$$

Experimental Arrays are made of various PV coupled cell and to find the attributes at PV array output the additional parameters have to be included is displayed in fig 1. characters is

The primary mathematical statement after adding

$$
I=I_{p v}-I_{o}\left[\exp \left(\frac{V+I R_{s}}{V_{t} n}\right)\right]-\frac{V+I R_{s}}{R_{p}}
$$

Where,

$I_{\text {proceli }}=$ Current produced from the daylight

$I_{\mathbb{G}}=$ Shotkey equation of diode represented in equation (2)

I = PV cell output current

$\mathrm{q}=$ Magnitude of elementary charge $\left(1.602176 * 10^{-19} \mathrm{C}\right)$

$\mathrm{V}=$ Solar Cell Voltage

$\mathrm{k}=$ Boltzmann factor $\left(1.3806503 * 10^{-22} \mathrm{~J} / \mathrm{K}\right)$

$\mathbb{R}_{g}=$ Series Resistance of PV cell

$V_{t}=$ Output voltage

$\mathrm{n}=$ Ideality factor of diode

$\mathbb{R}_{y}=$ Parallel Resistance of PV cell

$I_{\text {Qcell }}=$ Leakage current of diode

$\mathrm{T}=$ Temperature of $\mathrm{P}-\mathrm{N}$

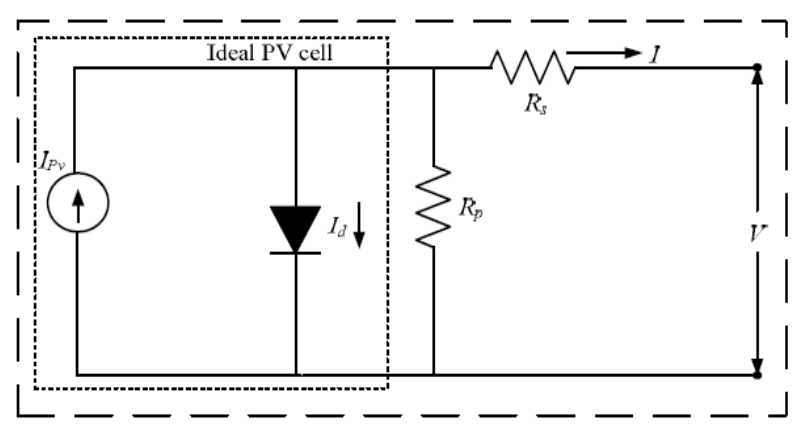

Fig. 1. Solar cell circuit diagram

$R_{\mathrm{p}}$ is maximum for solar cell with high quality and $\mathbb{R}_{g}$ is minimum. Scrutinize the 3 significant parameters (ie.,) open circuit voltage $\left(\mathbb{V}_{\infty c}\right)$, fault current $\left(\mathbb{I}_{\varepsilon \varepsilon}\right)$ and MPP. The PV apparatus is primly affected by irradiation level and degree and the characteristics of internal device [14]. Fig. 2 exhibits the V-I characteristics and P-V characteristics of Solar rely on MPPT, fault current, open circuit voltage.

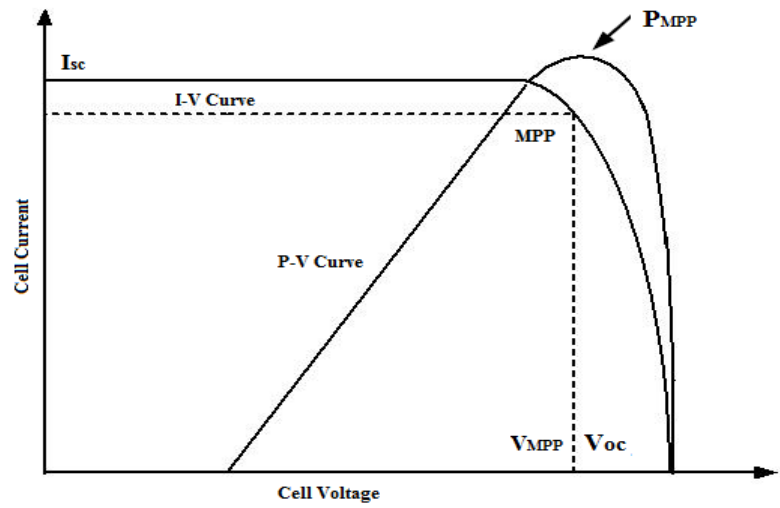

Fig. 2. VI and PV characteristics curve

\section{LUO CONVERTER DESIGN}

This converter is utilized for converting DC power at one level of voltage to another level. At present power electronic devices need supply of power with high reliability, high efficiency, and low input ripple. Parasitic elements in DC-DC converter limit the potential and efficiency. To outperform the above mentioned limitations DC-DC Luo converter is constructed. Fig. 3 displays the circuit figure of Luo converter. In power circuit the power switch IGBT is denoted as $\mathrm{S}$ and the freewheeling diode is denoted by $\mathrm{D}$. the passive elements used for power depository are Inductors L1, L2, and capacitors $\mathrm{C} 1, \mathrm{C} 2, \mathrm{R}$ is the load. This operates in both operations.

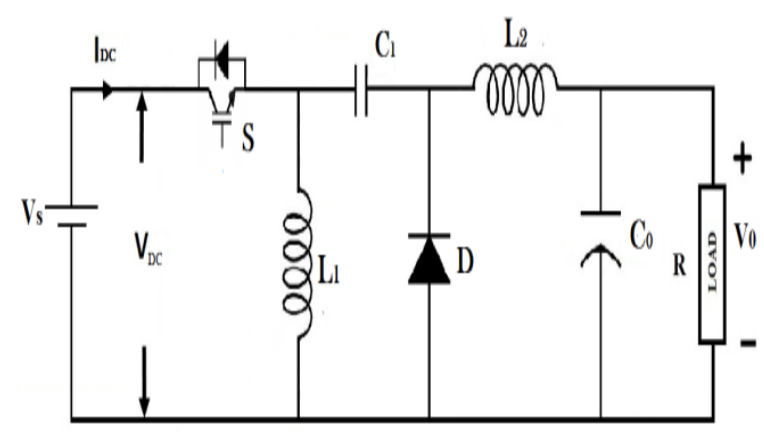

Fig. 3. Design of DC-DC Luo converter

The switch of the converter is ON while in operation mode, supply voltage charges inductorL1. At same time energy from source is absorbed by inductor L2 and capacitorC1. When switch is off, source current is zero, whereas current in L_1 flows through diode to charge capacitor C1, current in L2flows through C2, R and D to keep it in progressive way.

In discontinuous conduction mode, Diode is in OFF state, whereas inductor discharges through V0and L2. 
The energy is stored and delivered to the load from output stage and the switching voltage is smoothened to generate a stable output voltage. Inductors in Luo converter have a basic DC resistance (DCR) which affects the outcome voltage. Hence inductor with low DCR is used to enhance the performance of converter. Output capacitance value of Luo converter is increased to minimize the voltage ripple [15]. Formula calculation for duty cycle and output voltage Duty cycle

$D=\frac{T_{0 n s}}{T}$

Output voltage

$V_{0}=\frac{D}{1-D} V_{W}$

\section{ANN MAXIMAL POWER POINT TRACKING}

MPPT is utilized to extricate the highest energy of solar frame with a view to PV irradiation and climate changes at a specific timing with MPPT controller. A lot of formula have been experimented to check the MPP. Many of the prevailing algorithms experiences fault tracking, slow tracking and oscillations which minimize the efficiency.

To avoid the above mentioned cons ANN based MPPT is utilized in the developed method. The execution and efficiency of the system is maximized by utilizing ANN based MPPT. A trained Artificial Neural Network is coupled to evaluate the irradiation and climatic change from PV voltage and current signals [16].

Artificial Neural Networks (ANN) is nonlinear structures used widely in control systems. ANN is computational models inspired by biological neurons. It uses cascaded integrated nodes which applies the mathematical operations to input or output. Many learning mechanisms are present to make the ANN gain knowledge. Artificial Neural Networks are designed by using basic principles [18-19]. For detection of data ANN are trained and also comprehend the output and input relationship. The operation of ANN is carried by Initialization, training, validation and testing. ANN constitutes of three layers with many integrated nodes with an activation function. Flow chart of ANN algorithm is shown in fig. 4.

The three layers are namely input layer, hidden layer, output layer. The input character is fetched for evaluation and it does not change the contents in the input data. In hidden layer the input nodes are coupled to each node of layer, the process takes place by weighted connection. In output layer the active nodes generating the output integrate and transform the data to produce output values. Activation function is used for non linear operations. For monitoring output from reaching maximum value, transfer function is utilized. Thus ANN computes the value of switching angles to get low THD. The algorithm for ANN explains the operation of the system.

Step 1: Selection of changing angle for input data set.

Step 2: Input data are trained in ANN network and differentiate the actual output with desired output.

Step 3: Accuracy of trained ANN is evaluated and the new samples of data are tested. ANN testing plays a vital role in
ANN execution.

Step4: After evaluation best switching angle is obtained else process is repeated.

Artificial Neural Network is developed and experimented. In MPPT the ANN input can be PV module parameters such as PV voltage or PV current. Output is referred as Reference signal. There might be mono or multiple references signals. Among which duty cycle signal is used for DC-DC Luo converter to operate at or near to MPP. The result of the simulation we can get input and output data.

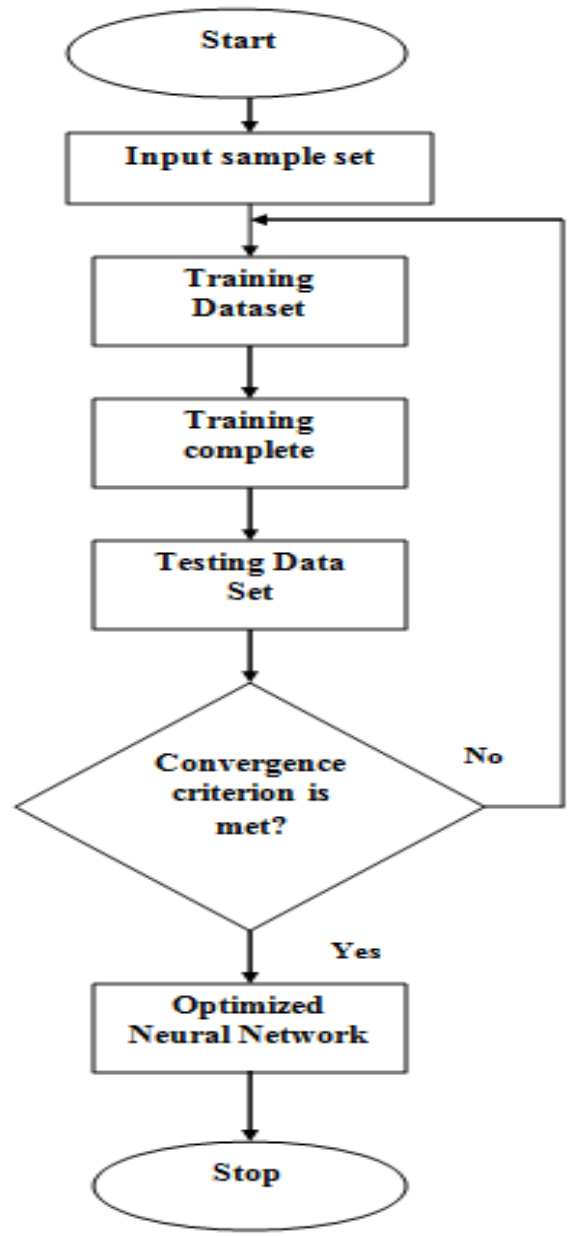

Fig. 4. Flow chart of ANN algorithm

Neural Network Toolbox from MATLAB software tool is utilized to produce trained and test data of the Neural Network. Using the matlab tool the data of current and voltage of PV are used to compute switching angles.

\section{SEVEN LEVEL INVERTER TOPOLOGY H-BRIDGE}

H-bridge seven level inverter which is single phase was designed. It constitutes traditional single phase H-bridge seven level inverter, IGBT and a capacitor voltage divider formed from $C_{1}, C_{2}, C_{\mathbb{Z}}$. The transformed $\mathrm{H}$-bridge methodology is primarily beneficial over other methodology shown in fig .5, whereas it has minimum number of power IGBT switches, power diodes and least number of capacitors connected to the grid. 


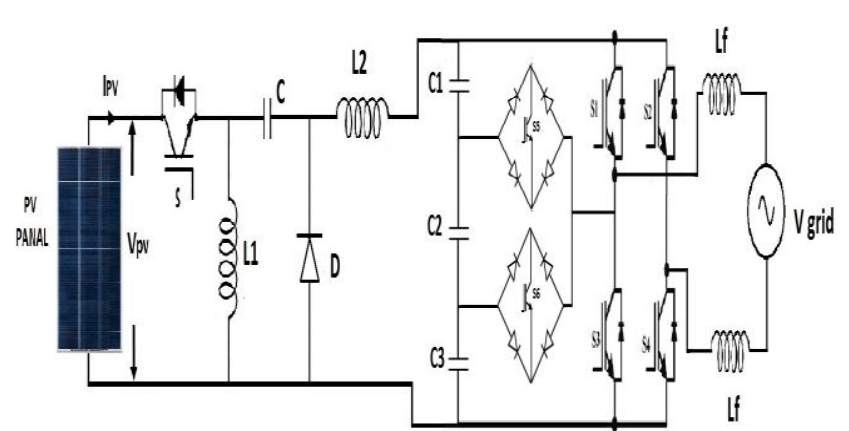

Fig. 5. Grid connected single phase seven level inverter

The PV module is integrated to the inverters with DC-DC Luo converter. The inverter generates the power and delivers to the network. Voltage from PV module is very low when compared to grid voltage hence DC-DC Luo converter is used. DC bus with high voltage is required to make sure whether power flows from PV module to grid. Inorder to drain the injected current into network a filtering inductance $L_{f}$ was utilized. Appropriate inverter switching can generate sevenlevels of output voltage $\left(V_{d e} \frac{2 V_{d r}}{a} V_{d r}, 0_{v}-V_{d e^{v}}-\frac{2 V_{d r}}{a}{ }_{a}-\frac{V_{d r}}{a}\right)$ for dc supply voltage. In the MLI all the voltage sources are in series with other voltage sources by H-bridge network. Table-I exhibits the switching functions which produce seven levels of output voltage.

Table- I: Switching condition of output voltage

\begin{tabular}{|l|c|c|c|c|c|c|}
\hline \multicolumn{1}{|c|}{$V_{0}$} & $S_{1}$ & $S_{2}$ & $S_{3}$ & $S_{4}$ & $S_{5}$ & $S_{6}$ \\
\hline$V_{d c}$ & on & off & off & on & off & off \\
\hline $2 V_{d c} / 3$ & off & off & off & on & on & off \\
\hline$V_{d c} / 3$ & off & off & off & on & off & on \\
\hline 0 & off & off & on & on & off & off \\
\hline $0^{*}$ & on & on & off & off & off & off \\
\hline$-V_{d c}$ & off & on & off & off & on & off \\
\hline$-2 V_{d c} / 3$ & off & on & off & off & off & on \\
\hline$-V_{d c} / 3$ & off & on & on & off & off & off \\
\hline
\end{tabular}

A typical technique for modulation is implemented to produce PWM switching signal. A carrier signal ( $\left.\mathbb{V}_{\text {carryigy }}\right)$ is differentiated with three reference signals $\left(V_{\text {ref }}\right)$. The offset value of reference signal is in phase, which is as same as the carrier signal amplitude. Reference signals have similar frequency and amplitude. All the relating signals are differentiated with transmitter signals. If one reference signal surpass the crest extent of carrier signal, then other reference was differentiated with carrier signal until it outreach the crest extent of transmitter signals. Hence forth third reference signal will be in action and differentiated with carrier signal till zero is attained. After this second reference will be differentiated till zero is achieved and the same occurs for the first reference signal.

For fundamental frequency with one cycle the developed inverter functions in six modes. Fig. 6 shows the output voltage signal for one cycle.

The six modes are explained as given below Mode 1: $0<\omega t<\theta_{1}$ and $\theta_{4}<\omega t<\pi$
Mode 2: $\theta_{1}<\omega t<\theta_{2}$ and $\theta_{n}<\omega t<\theta_{4}$

Mode 3: $\theta_{2}<\omega t<\theta_{a}$

Mode 4: $\pi<\omega t<\theta_{5}$ and $\theta_{9}<\omega t<2 \pi$

Mode 5: $\theta_{5}<\omega t<\theta_{6}$ and $\theta_{7}<\omega t<\theta_{9}$

Mode 6: $\theta_{6}<\omega t<\theta_{7}$

The phase angle of the inverter rely on modulation index $M_{a}$, for mono reference signal and mono transmitter signal the modulation indices is defined as

$$
M_{\mathrm{a}}=\frac{A_{\mathrm{m}}}{A_{\mathrm{c}}}
$$

Hence for mono reference signal and two transmitter sign the modulation indices is

$$
M_{\alpha}=\frac{A_{\mathrm{m}}}{2 A_{e}}
$$

So the developed seven level PWM MLI uses three transmitter signals, the modulation indices will be

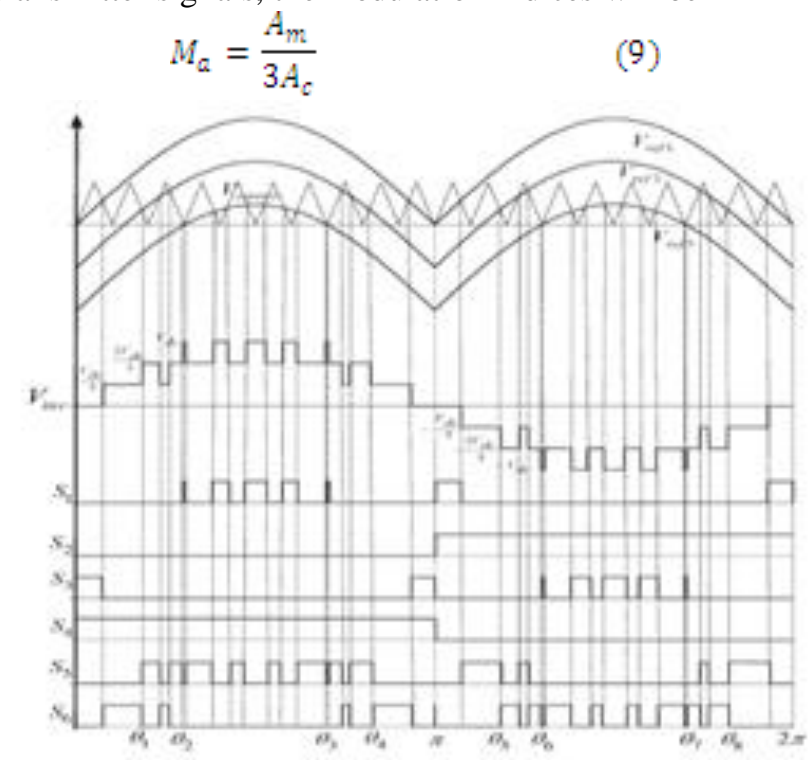

Fig. 6. Switching level of seven level inverter

Fig. 7 depicts the pattern of inverter changing. Switches $S_{1}, S_{9 x} S_{5, x} S_{6}$ will operate at the rate of messenger signal frequency. $S_{2 \text { and }} S_{4}$ will operate at a oscillation similar to base recurrence.

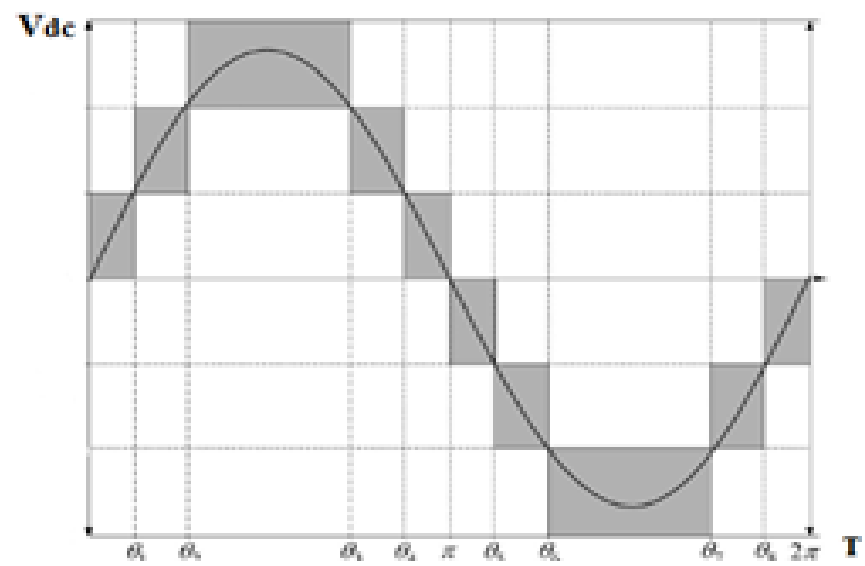

Fig. 7. Output voltage of seven level inverter 
Where,

$A=$ crest to crest value of messenger signal

$A_{\mathrm{m}}=$ crest value of reference voltage signal

Total Harmonic distortion and switching angle are evaluated and given to the PWM pulse generators of IGBT switches inorder to get reduced THD. The developed inverter is used to decrease the THD and to achieve the multiple desired voltage levels using ANN based MPPT.

\section{SIMULATION RESULTS}

In this system is validated with matlab simulation software. The high gain Luo converter is self regulation by ANN based MPPT formula to track the maximum energy from the solar system.

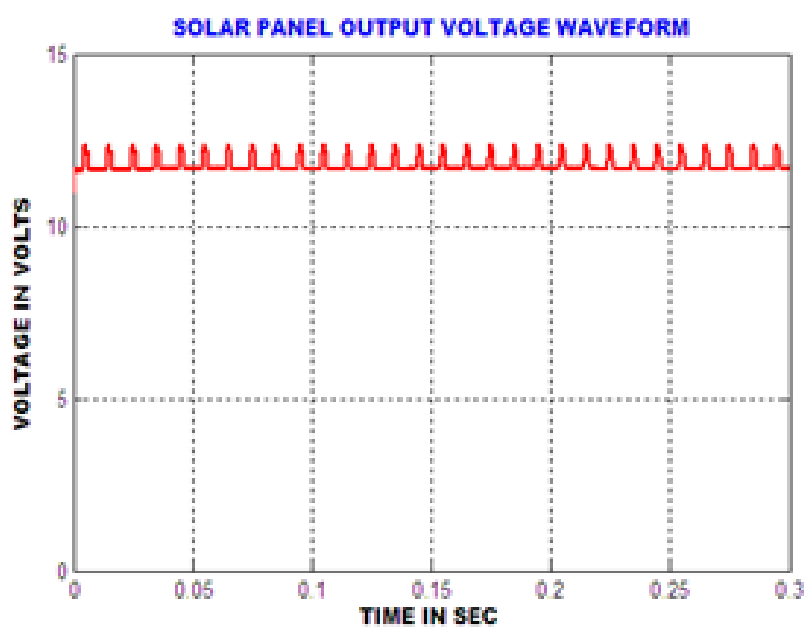

Fig. 8. Gross voltages from the PV system

Fig. 8. Depicts the desired voltage from the PV system, this voltage contains maximum order harmonics and fluctuations due to temperature and irradiance variation.

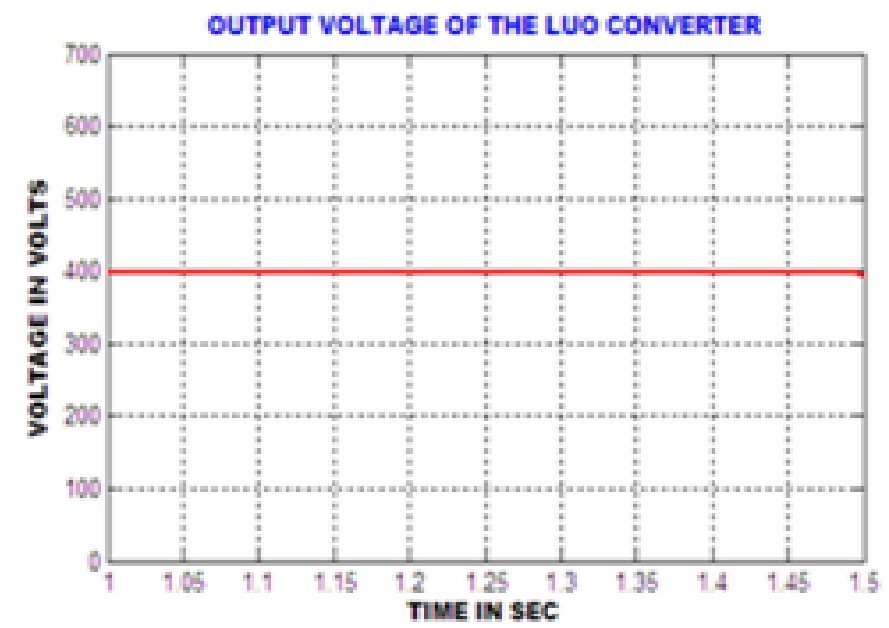

Fig. 9. Output voltage of the LUO converter

Fig 9. Depicts the desired voltage of the Luo converter using ANN based MPPT algorithm, this formula retain constant voltage to the seven level cascaded MLI.

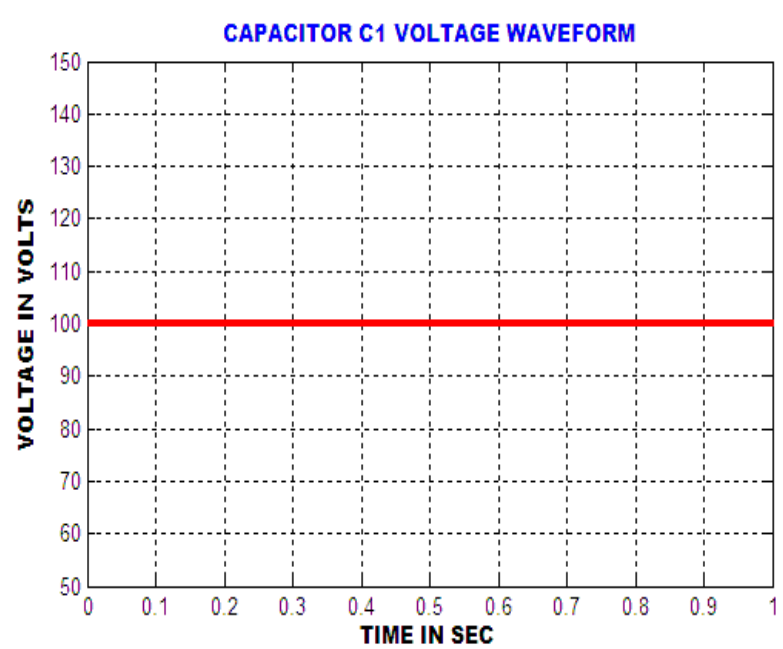

Fig. 10. Voltage across the capacitor $\mathrm{C} 1$ in the MLI

Electrical power is converted to mechanical power and addition to losses of frictional as well as power losses (Joules/sec).

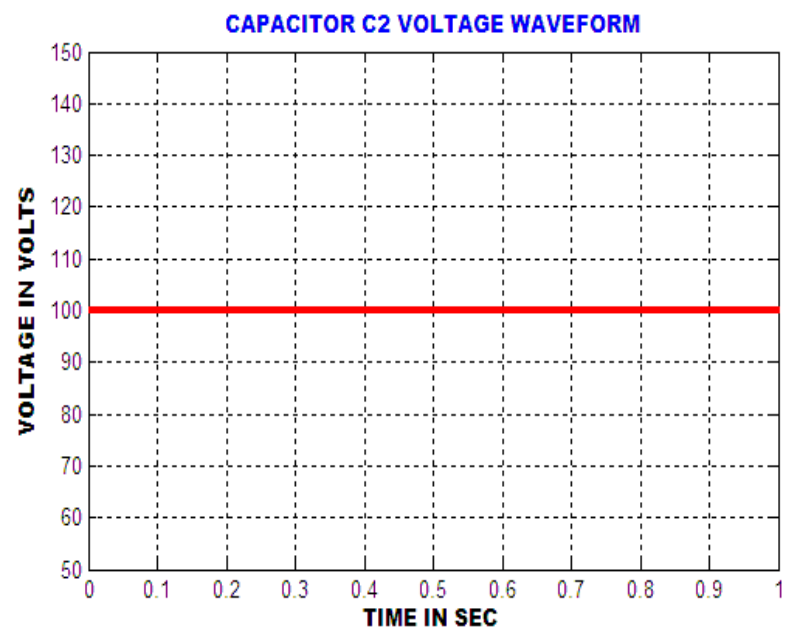

Fig. 11. Voltage across the capacitor $\mathrm{C} 2$ in the MLI

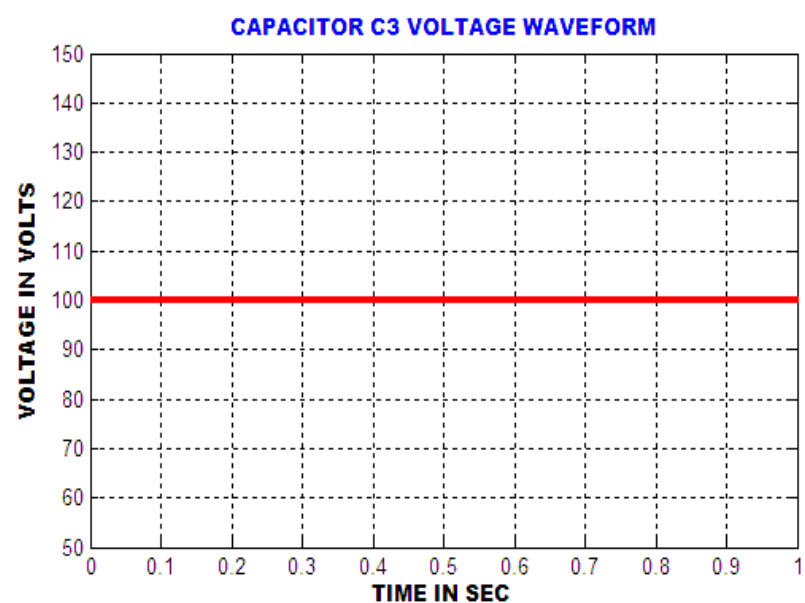

Fig. 12. Voltage across the capacitor $\mathrm{C} 3$ in the MLI 


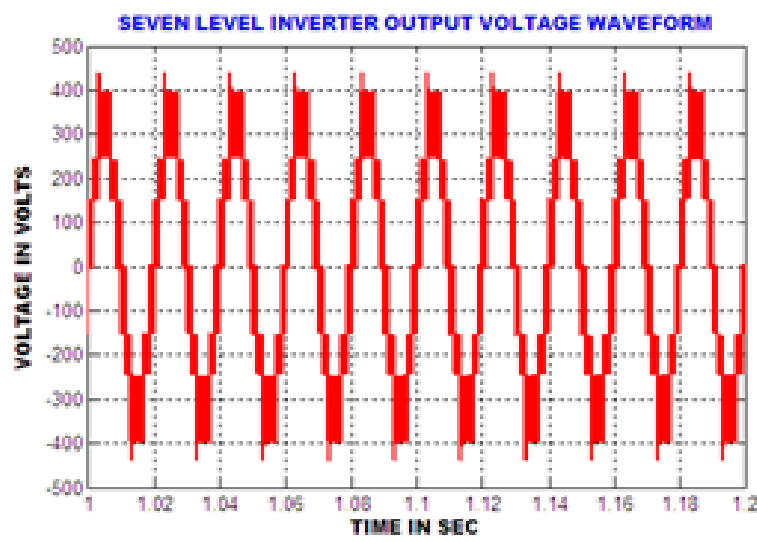

Fig. 13. Seven level inverter output voltage waveform

Fig. 13 Shows seven level output voltage of the proposed MLI using multi carrier modulation.

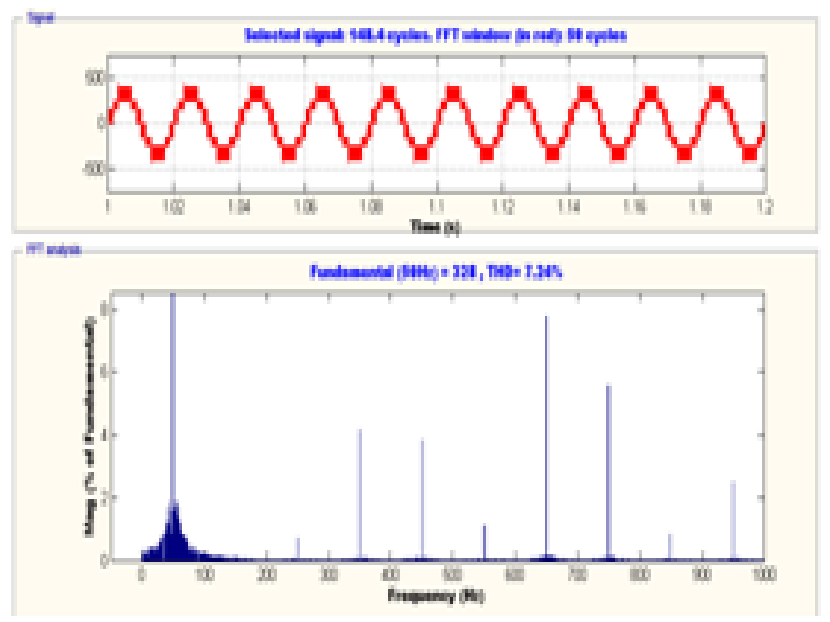

Fig. 14. Seven level inverter output voltage THD waveform

The figure 14. Shows the THD value of cascaded seven level inverter desired voltage THD adopting Multi carrier modulation techniques.

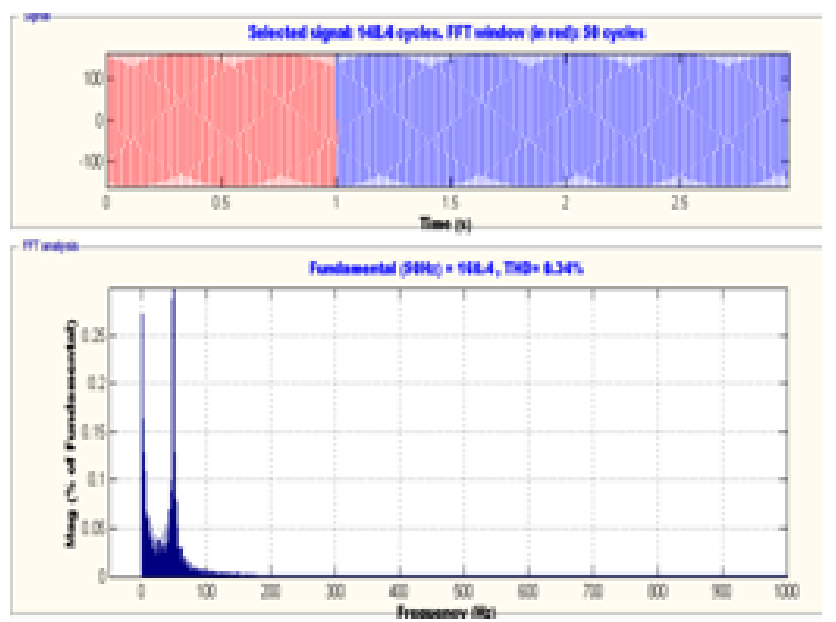

Fig. 15. Single phase grid output voltage THD waveform

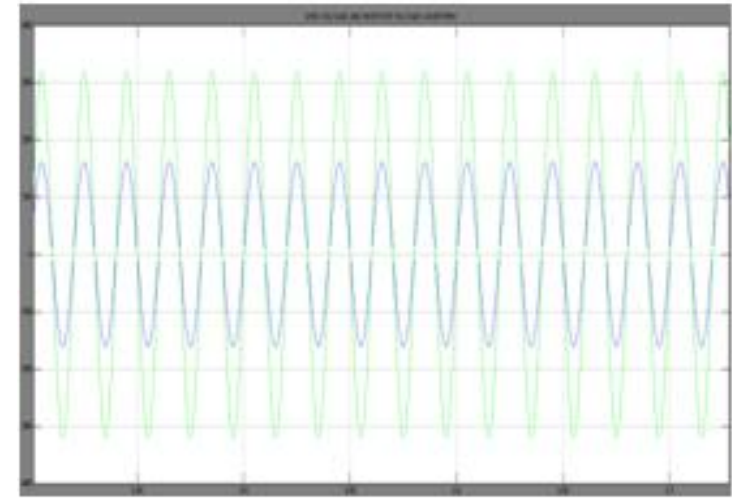

Fig. 16. Single phase grid output voltage and syncronization waveform

\section{CONCLUSION}

The suggested high gain converter decreases the potential ripples coming through the PV system. The ANN-based MPPT formula receives greater energy from the solar system. The proposed reduced switch multilevel inverter has several advantages compared to conventional schemes, the common DC link voltage is divided into three DC sources using split capacitor to get the output voltage of seven level. The multicarrier based PWM control technique is meant to get the output voltage of seven levels. Phase synchronization is achieved using the PI controller. The proposed inverter has reduced the THD with only $7.34 \%$ and also maintains less energy condition issues in the network. The Matlab simulation is validated the output results for the proposed reduced switch Multi-stage inverter for PV structure linked to a phase.

\section{REFERENCES}

1. T. Esram and P. L. Chapman, "Comparison of Photovoltaic Array Maximum Power Point Tracking Techniques," IEEE trans. Energy Convers, vol. 22, no. 2, pp. 439-449, 2007.

2. P. V. N. M. Kumar, P. M. Kishore and R. K. Nema, "Simulation Of Cascaded H-Bridge Multilevel Inverters For PV Applications," International Journal of ChemTech Research, vol. 5, no. 2, pp. 918-924, 2013.

3. V. B. Manimaran. "Design And Implementation Of Solar-Wind Combo for Hybrid Energy Application,” International Journal of MC Square Scientific Research, vol.5, no.1, Nov 2013.

4. Brito, M. A. G. Galotto, L. Sampaio, L.P. de Azevedo e Melo, and C.Canesin, "Evaluation of the Main MPPT Techniques for Photovoltaic Applications," IEEE Transactions, Ind. Electron, vol. 3, pp. 1156-1167, 2013

5. M. Koteswararao and P. Pawanputra, "Control Performance Evaluation of Solar PV Cells Connected to an AC Grid," Indian Streams Research Journal, vol. 3, no. 11, pp. 1-7, 2013.

6. M. Lina Elobaid, K. Ahmed k Abdelsalam, and E. Ezeldin E Zakzouk "Artificial Neural Network based Photovoltaic MPPT technique: A Survey,"IET Renewable Power Generation, Vol. 9, no. 8, pp. 1043-1063, 2015 .

7. L. Bouselham, B. Hajji, and H. Hajji, "Comparative Study of Different MPPT Methods for Photovoltaic System," 3rd International Renewable and Sustainable Energy Conference (IRSEC), pp: 1-5, 2015.

8. Hong Hee Lee, DinhKhoa, Dzung, Phuong, and Truong Dan Vu "The New Maximum Power Point Tracking Algorithm using ANN-Based Solar PV Systems," IEEE Transactions, Vol. 1, pp 2179-2184, 2010.

9. K. P. Panda, B. P. Sahu, D. Samal and Y. Gopal, "Switching Angle Estimation using GA Toolbox for Simulation of Cascaded Multilevel Inverter," International Journal of Computer Applications, vol. 73, no. 21, pp. 21-26, 2013. 
10. S. Daher, J. Schmid, and F. L.M. Antunes, "Multilevel inverter topologies for stand-alone PV systems," IEEE Trans. Ind. Electron, vol. 55, no. 7, pp. 2703-2712, 2008.

11. A. Jain, N. Khatri, P. Shrivastavand, and A. Mahor, "THD Analysis of Cascaded H-Bridge Multilevel Inverters in Fuel Cell Applications," IEEE International Conference on Computer, Communication and Control, 2015.

12. J. Dixon and L. Moran, "High-level multistep inverter optimization using a minimum number of power transistors," IEEE Trans. Power Electron, vol. 21, no. 2, pp. 330-337, 2006.

13. N. Vijayalakshmi, "Photovoltaic Fed Multilevel Inverter Design Using PODPWM Technique for Improved Power Quality," International Journal Of Advances In Signal And Image Sciences, vol. 5, no. 1, 2019, pp. 8-14.

14. A. Sarwar and M. S. J. Asghar, "Simulation and Analysis of a Multilevel Converter Topology for Solar PV Based Grid Connected Inverter," Renewable Energy and Smart Grid, vol. 2, no. 1, pp. 56-62, 2011.

15. N. Prabaharan and K. Palanisamy, "Analysis and integration of multilevel inverter configuration with boost converters in a photovoltaic system," Energy Conversion and Management, vol. 128, pp. 327-342, 2016.

16. E. Beser, B. Arifoglu, S. Camur and E. K. Beser, "A gridconnected photovoltaic power conversion system with single-phase multilevel inverter," Solar Energy, vol. 84, no. 12, pp. 2056-2067, 2010.

17. A. Manikandan, and N. Vadivel, "Design and Implementation Of Luo Converter For Electric Vehicle Applications," International Journal of Engineering Trends and Technology, Vol. 4, no. 10, pp. 4437-4441, 2013.

18. B. Pakkiraiah and G.D. Sukumar," A New Modified Artificial Neural Network Based MPPT Controller for the Improved Performance of an Asynchronous Motor Drive," Indian Journal of Science and Technology, vol. 9, pp. 1-10, 2016.

19. E. Bektas and H. Karaca, "GA Based Selective Harmonic Elimination for Five-Level Inverter Using Cascaded Hbridge Modules," International Journal of Intelligent Systems and Applications in Engineering, vol. 4 no. 2, pp. 29-32, 2016.

\section{AUTHORS PROFILE}

S.Prakash he received his B.E in Electrical and

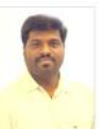
Electronics Engineering (2006) from Government college of Engineering and M.E in Power system Engineering (2008) from Annamalai University. He has more than 10 publications in the field of Power System Engineering. He is research scholar in Department of Electrical Engineering, Vinayaka Missions Research Foundation. His research interests includes special Electrical Machines and Drives.

N.P.Gopinath he received his B.E in Electrical and Electronics Engineering (2009) from Noorul Islam College of Engineering and M.Tech in Power Electronics \& Drives (2013) from SRM University. He has more than 10 publications in the field of Power Electronics. He is research scholar in Department of Electrical Engineering, Vinayaka Missions Research Foundation. His research interests include Control System Applications to Power Electronics.

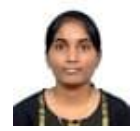

B.Kalaiselvi She received her B.E in Electrical and Electronics Engineering (2013) from SRM Valliammai Engineering College and M.E in Power system Engineering (2016) from Anna University. She is research scholar in Research Foundation. Department of Electrical Engineering, Vinayaka Missions 